\title{
HOSPITALIDADE URBANA E PLANEJAMENTO TURÍSTICO: OS CINCO ESTADOS MAIS HOSPITALEIROS DO BRASIL EM FOCO
}

\author{
Valéria Ferraz Severini \\ Doutora em Arquitetura e Urbanismo pela \\ Faculdade de Arquitetura e Urbanismo da \\ Universidade de São Paulo (FAU-USP). \\ Pós-doutoranda do Programa de Pós-Graduação \\ em Turismo da \\ Escola de Artes, Ciências e Humanidades da \\ Universidade de São Paulo - EACH-USP \\ valferraz@yahoo.com
}

Alexandre Panosso Netto

Livre-docente pela EACH-USP.

Professor na Escola de Artes, Ciências e Humanidades

da Universidade de São Paulo - EACH-USP.

panosso@usp.br

Objetivos: Este artigo tem como objetivo principal investigar se as estratégias de planejamento turístico utilizadas pelos cinco estados mais hospitaleiros do país incentivam a elaboração de Planos Diretores. Tem-se ainda como objetivo secundário aprofundar os estudos que relacionam a hospitalidade urbana às políticas públicas de desenvolvimento urbano.

Metodologia/Abordagem: Utilizou-se no trabalho pesquisa documental e bibliográfica. A coleta de leis, decretos e planos foi obtida através da internet, mais especificamente pelos sites do Ministério do Turismo e dos Órgãos Estaduais de Turismo dos cinco estados analisados.

Originalidade/Relevância: $\mathrm{O}$ trabalho apresenta a hospitalidade urbana como uma solução inovadora e alternativa para a gestão de cidades turísticas. A pesquisa destaca a importância das leis que regulam o uso e ocupação do solo na condução de um planejamento turístico mais justo e acolhedor para moradores e turistas.

Principais resultados: Apesar de ser uma obrigatoriedade, os resultados sugerem que a elaboração de Planos Diretores em "cidades com especial interesse turístico" não é condição essencial para que as cidades recebam o "selo" de cidades turísticas e passem a contar com recursos financeiros, técnicos e humanos. A pesquisa reforçou o papel do Estado como anfitrião urbano ao demonstrar sua função de agente regulador do uso e ocupação do solo, equilibrando a disputa do território turístico e evitando a especulação imobiliária.

Contribuições teórico-metodológicas: $\mathrm{O}$ artigo apresenta o lado prático da ciência da hospitalidade ao demonstrar a implementação dos atributos espaciais da hospitalidade urbana nas políticas públicas de desenvolvimento urbano de cidades turísticas.

Palavras-chave: Hospitalidade urbana. Políticas públicas. Plano diretor. Cidade turística. Espaço público. 


\title{
Cite como
}

American Psychological Association (APA)

Severini, V. F., \& Panosso Netto, A. (2020, set./dez.). Hospitalidade urbana e planejamento turístico: os cinco estados mais hospitaleiros do Brasil em foco. PODIUM Sport, Leisure and Tourism Review, São Paulo, 9(Edição Especial), 1-27. https://doi.org/10.5585/podium.v9i4.16743.

\section{URBAN HOSPITALITY AND TOURISM PLANNING: THE MOST HOSPITABLE STATES OF BRAZIL IN FOCUS}

\begin{abstract}
Objectives: This article aims to investigate whether the tourism planning strategies used by the five most hospitable states in the country encourage the elaboration of Master Plans. Its secondary objective is to deepen the studies that relate urban hospitality to public policies of urban development.
\end{abstract}

Methodology / Approach: Documentary and bibliographical researches were used in the work. The collection of laws, decrees and plans was obtained through the internet, more specifically through the websites of the Ministry of Tourism and the State Tourism Organizations of the five states analyzed.

Originality / Relevance: The work presents urban hospitality as an innovative and alternative solution for the management of tourist cities. The research selected the importance of zoning laws in conducting a fairer and more welcoming tourism planning for residents and tourists.

Main results: Although it is mandatory, the results suggested that the elaboration of Master Plans in "cities with special tourist interest" are not essential for the cities receives the "seal" of tourist cities and now use financial, technical and human resources. The research reinforced the role of the state as urban host and demonstrated its role as a regulator of land use and occupation, balancing a dispute of tourist territory and avoiding real estate speculation.

Theoretical and methodological contributions: The paper presents the practical side of the science of hospitality by demonstrating the implementation of the spatial attributes of urban hospitality in public policies of urban development of tourist cities.

KeywordS: Urban hospitality. Public policy. Master plan. Tourist city. Public space.

\section{HOSPITALIDAD URBANA Y PLANIFICACIÓN TURÍSTICA: LOS CINCO ESTADOS HOSPITALARIOS DE BRASIL EN FOCO}

\section{RESUMEN}

Objetivos: Este artículo tiene como objetivo principal investigar si las estrategias de planificación turística utilizadas por los cinco estados más hospitalarios del país fomentan la elaboración de planes maestros. El objetivo secundario también es profundizar los estudios que relacionan la hospitalidad urbana con las políticas públicas para el desarrollo urbano.

Metodología / Enfoque: Se utilizó investigación documental y bibliográfica en el trabajo. La recopilación de leyes, decretos y planes se obtuvo a través de Internet, más específicamente a través de 
los sitios web del Ministerio de Turismo y los organismos estatales de turismo de los cinco estados analizados.

Originalidad / Relevancia: El trabajo presenta la hospitalidad urbana como una solución innovadora y alternativa para la gestión de las ciudades turísticas. La investigación destaca la importancia de las leyes que regulan el uso y la ocupación de la tierra para llevar a cabo una planificación turística más justa y acogedora para los residentes y turistas.

Resultados principales: A pesar de ser una obligación, los resultados sugieren que la elaboración de planes maestros en "ciudades con especial interés turístico" no es una condición esencial para que las ciudades reciban el "sello" de las ciudades turísticas y tengan recursos financieros, técnicos y humanos. La investigación reforzó el papel del estado como anfitrión urbano al demostrar su papel como regulador del uso y la ocupación del suelo, equilibrando la disputa sobre el territorio turístico y evitando la especulación inmobiliaria.

Contribuciones teóricas y metodológicas: El artículo presenta el lado práctico de la ciencia de la hospitalidad al demostrar la implementación de los atributos espaciales de la hospitalidad urbana en las políticas públicas de desarrollo urbano de las ciudades turísticas.

Palabras clave: Hospitalidad urbana. Políticas públicas. Plan maestro. Ciudad turística. Espacio público.

\section{Introdução}

Este artigo tem como objetivo principal investigar se as estratégias de planejamento turístico dos cinco estados mais hospitaleiros do país encorajam a elaboração de Planos Diretores. A pesquisa adentra o campo da hospitalidade urbana explorando suas convergências com políticas públicas de desenvolvimento urbano detentoras de ferramentas capazes de qualificar o espaço público.

A hospitalidade é um aspecto muito valorizado pelo brasileiro. É fato que certas características do nosso comportamento agradam os turistas (MENDES; WADA, 2016). A simpatia, o sorriso fácil, o gosto pela agitação e pela diversão são inerentes ao povo brasileiro. Contudo, a ciência da hospitalidade vai muito além do bom humor e da alegria. Falar em hospitalidade é dar conta das inúmeras implicações decorrentes do ato de receber, hospedar, alimentar e entreter pessoas fora de seu habitat de origem num determinado espaço (CAMARGO, 2003).

Espaço esse que, no caso da esfera da hospitalidade urbana, é o espaço público. Um espaço comum à todos, de uso coletivo, que não exige reservas e nem possui horário de funcionamento (FERRAZ, 2013). Para sermos de fato um povo hospitaleiro precisamos qualificar esse espaço. 
A condição de cidade hospitaleira está intimamente ligada à valorização do desenho urbano, refletida na oferta de equipamentos e espaços públicos de qualidade e no estabelecimento de uma série de regras que garantam que as construções em âmbito privado dialoguem de forma harmônica com o espaço público (FERRAZ, 2013). Isso incrementa os ambientes formais e informais de encontros e de trocas espalhados pelas cidades e contribui para que o local seja atraente e acolhedor não só para turistas, mas também, e essencialmente, para moradores.

A atividade turística é uma prática socioespacial que envolve sujeitos sociais de várias ordens e com expectativas diferentes (BARRIOS, 1986). Moradores, turistas, comerciantes, empresários e poder público, ocupam e disputam o mesmo território. Porém, não necessariamente de forma equilibrada.

A dinâmica do mercado imobiliário nas cidades brasileiras mantém uma forte relação com as atividades do setor turístico, sobretudo em cidades litorâneas (SILVA \& FERREIRA, 2007). Diante da forte pressão de empresários desse setor, torna-se essencial que políticas públicas de desenvolvimento urbano de cidades turísticas estabeleçam diretrizes para que o território seja ocupado de forma justa e sustentável. Para Cruz (1999), se o espaço desempenha o papel de reprodutor material da organização social, cabe ao Estado conciliar esses interesses organizando o território para que todos se beneficiem. Trata-se, antes de tudo, de uma ação de política pública de Estado e não somente uma ação momentânea de governo particulares (LOHMANN; PANOSSO NETTO, 2012).

Dentro da perspectiva da hospitalidade urbana, cabe ao anfitrião urbano, representado pela figura do gestor público, implantar ou consolidar uma série de ações de reconhecimento e fortalecimento da qualidade urbanística (YÁZIGI, 2001; FERRAZ, 2013). Entre essas ações está a elaboração de leis que definam regras de uso e ocupação do solo, como o Plano Diretor e a Lei de Zoneamento.

As questões relacionadas à terra foram de fato regulamentadas com a Constituição de 1988, por meio dos artigos 182 e 183, que estabeleceram normas sobre a regulamentação do uso da propriedade criando diretrizes para as políticas urbanas nacionais. Mas sua consolidação só veio em 2001 com a regulamentação da Lei 10.257/2001, conhecida como Estatuto da Cidade, que incorporou uma série de instrumentos urbanísticos e o conceito de função social da propriedade e passou a incentivar e encorajar a participação popular na elaboração dos planos e projetos (ROLNIK, 2009). Pela primeira vez, o país assume que a terra urbana deve servir 
para benefício da coletividade e não apenas ao interesse do proprietário. Ou seja, o interesse individual é subordinado pelo interesse coletivo.

O Plano Diretor passou a ser lei municipal fundamental para nortear o crescimento da cidade a partir de vários aspectos, entre eles: físicos, econômicos, sociais, ambientais e urbanísticos. É no Plano Diretor, por exemplo, que são estabelecidas as diretrizes básicas para as políticas de habitação, de mobilidade urbana, de paisagem urbana, de desenvolvimento econômico (o que inclui as políticas de turismo) e de qualificação ambiental. Mas, sobretudo, é no Plano Diretor que são delineadas as diretrizes gerais de organização territorial e, por consequência, as regras básicas de ocupação do solo em âmbito privado. Essas regras norteiam a legislação urbanística ${ }^{1}$ do município e podem incorporar os conceitos de hospitalidade urbana (SEVERINI \& VARGAS, 2017).

Trata-se, por exemplo, de regras urbanísticas capazes de restringir o gabarito (altura dos edifícios) em áreas de especial interesse turístico, incentivar o zoneamento de uso misto em áreas dotadas de infraestrutura urbana, garantir a permeabilidade física nos empreendimentos à beira mar, estimular a preservação de edifícios de valor histórico etc.

A exigência na elaboração de Planos Diretores em "cidades integrantes de áreas de especial interesse turístico" é um indicativo que a atividade turística interfere diretamente na ocupação do território e, por consequência, afeta a vida das pessoas. Trata-se de um instrumento essencial para garantir que o desenvolvimento do turismo seja justo e sustentável. Pois como lembra Oliveira (2014, p. 81):

(...) a construção da cidade turística nem sempre é para atender à expectativa do morador local, mas às expectativas externas ao lugar, que buscam, a partir da construção de obras grandiosas, tornar a cidade mais competitiva, enquanto as obras de infraestrutura básicas que realmente interessam ao lugar, aos moradores, continuam inacabadas.

Diferentemente do que ocorre nas outras situações de obrigatoriedade ${ }^{2}$, não existe um critério objetivo que ajude a esclarecer quais são as cidades que se encaixam na categoria cidades turísticas. Não há especificação sobre as "áreas de especial interesse turístico" no Estatuto da Cidade, nem no Plano Nacional de Turismo ${ }^{3}$ e muito menos na Lei que estabelece

\footnotetext{
${ }^{1}$ Legislação urbanística é um conjunto de leis, decretos e planos que regulam o parcelamento, uso e ocupação do solo estabelecendo regras e limites para garantir que o espaço urbano seja um local agradável e que ofereça qualidade de vida.

${ }^{2}$ O Estatuto da Cidade exige a elaboração de Plano Diretor em quatro situações: (a) cidades com mais de vinte mil habitantes; (b) cidades integrantes de regiões metropolitanas e/ou aglomerações urbanas; (c) cidades integrantes de áreas de especial interesse turístico e; (d) cidades inseridas na área de influência de grandes empreendimentos com grande impacto ambiental.

${ }^{3}$ O Plano Nacional de Turismo 2018-2022 é o instrumento que estabelece diretrizes e estratégias para a implementação da Política Nacional de Turismo.
} 
as normas sobre a Política Nacional de Turismo (Lei 11.771/2008). Apenas a Lei $\mathrm{n}^{\circ}$. 6.513/1977, anterior ao Estatuto da Cidade, dispõe sobre a criação de "Áreas Especiais e de Locais de Interesse Turístico". Segundo o Capítulo I, Art.1 ${ }^{\circ}$, consideram-se de interesse turístico:

I - Os bens de valor histórico, artístico, arqueológico ou pré-histórico;

II - as reservas e estações ecológicas;

III - as áreas destinadas à proteção dos recursos naturais renováveis;

IV - as manifestações culturais ou etnológicas e os locais onde ocorram;

$\mathrm{V}$ - as paisagens notáveis;

VI - as localidades e os acidentes naturais adequados ao repouso e a prática de atividades recreativas, desportivas ou de lazer;

VII - as fontes hidrominerais aproveitáveis;

VIII - as localidades que apresentam condições climáticas especiais;

IX - outros que venham a ser definidos, na norma desta lei.

Os critérios acima mencionados não são claros. Seriam apenas as cidades que possuem bens de valor histórico, artístico, arqueológico ou pré-histórico tombados pelo Iphan (Instituto do Patrimônio Histórico e Artístico Nacional) que devem desenvolver seus Planos Diretores? $\mathrm{Ou}$ as cidades que possuem APP (Áreas de Preservação Permanente)? Isso demonstra a fragilidade das políticas públicas nacionais sobre o tema “cidades turísticas”. Para Lobo (2005), apesar de existirem alguns marcos sobre o tema, eles são dispersos, pouco articulados e de rasa aplicação no território. Como consequência, o planejamento da atividade fica a cargo dos Órgãos Estaduais de Turismo, que criam seus próprios mecanismos para estimular (ou não) a elaboração dos Planos Diretores nas cidades turísticas.

Diante desse cenário, investiga-se aqui os mecanismos e as estratégias utilizadas pelos Órgãos Estaduais de Turismo dos estados mais hospitaleiros do Brasil para incentivar as cidades turísticas a elaborarem seus Planos Diretores.

Tem-se como recorte espacial os cinco estados eleitos como os mais hospitaleiros do Brasil em 20194. São eles: Mato Grosso do Sul, Santa Catarina, Rio Grande do Sul, Paraná e São Paulo. Segundo a pesquisa realizada pelo Ministério do Turismo:

A hospitalidade lidera em avaliação positiva entre os 16 itens de infraestrutura e serviços pesquisados no estudo da demanda internacional do MTur. Somada aos alojamentos, gastronomia, restaurantes e aeroportos, que também influenciam a percepção do turista,

\footnotetext{
${ }^{4}$ No dia 29 de janeiro de 2019, dia da hospitalidade, o site do Ministério do Turismo divulgou os destinos nacionais com o 'modo de receber' mais bem avaliado em pesquisa com turistas estrangeiros. Fonte:

http://www.turismo.gov.br/\%C3\%BAltimas-not\%C3\%ADcias/12332-conhe\%C3\%A7a-os-cinco-estados-maishospitaleiros-do-brasil.html. Acessado em maio de 2019.
} 
compõe o conjunto de atributos fundamentais da boa experiência turística. Em 2017, por exemplo, o modo de receber do brasileiro recebeu aprovação de 98,1\% dos estrangeiros que visitaram destinos nacionais, maior percentual registrado nos últimos cinco anos (Ministério do Turismo, 2019).

$\mathrm{O}$ artigo foi estruturado em 4 (quatro) partes. Num primeiro momento foram relacionadas questões básicas de planejamento turístico com as discrepâncias na ocupação do território turístico. Em seguida, foi feita uma breve contextualização sobre os conceitos de hospitalidade urbana, apresentando de forma objetiva suas principais características e aproximando suas diretrizes à legislação urbanística. Depois abordou-se a metodologia utilizada. Posteriormente, foram analisados os critérios que os cinco estados mais hospitaleiros do Brasil utilizam para categorizar suas cidades turísticas e discutidas as estratégias utilizadas para o incentivo da elaboração de Planos Diretores.

Ao que tudo indica ainda há um longo caminho a ser percorrido pelos órgãos estaduais de turismo para que eles de fato passem a exigir a elaboração de políticas públicas de desenvolvimento urbano para àquelas cidades que se pretendem turísticas.

\section{REVISÕES DE LITERATURA}

\section{Planejamento turístico versus discrepâncias na ocupação do território}

Para Ruschmann (2001) a finalidade do planejamento turístico está em ordenar as ações humanas sobre uma localidade turística, bem como direcionar a construção de equipamentos e facilidades de forma adequada, evitando efeitos negativos nos recursos que possam destruir ou afetar sua atratividade. Isso reforça a necessidade de um tipo de ocupação no território de cidades turísticas de maneira a garantir o bem estar da população sem prejudicar o próprio atrativo.

A construção de edifícios sem controle de gabarito (instrumento urbanístico que controla a altura ou estipula o número de pavimentos de um edifício) é um exemplo de como a falta de planejamento pode prejudicar o turismo. A presença de prédios altos junto à orla pode gerar áreas de sombra na faixa de areia durante algumas horas do dia, alterando a temperatura do local e comprometendo o turismo (Ver Figura - 1). Seja nas avenidas à beira-mar ou em bairros históricos, a verticalização sem limites pode gerar impactos significativos na vizinhança e alterar o cotidiano dos moradores (LAPA, 2011). 
Já a implantação de resorts ou de grandes empreendimentos em quadras litorâneas, pode dificultar o acesso de moradores ao mar. Cabe ao Estado impor limites ou estabelecer regras para garantir o livre e franco acesso à orla e ao mar em qualquer sentido e direção (Ver Figura $-2)$.

Figura 1 - Croqui exemplificando as consequências de uma verticalização sem controle junto à orla

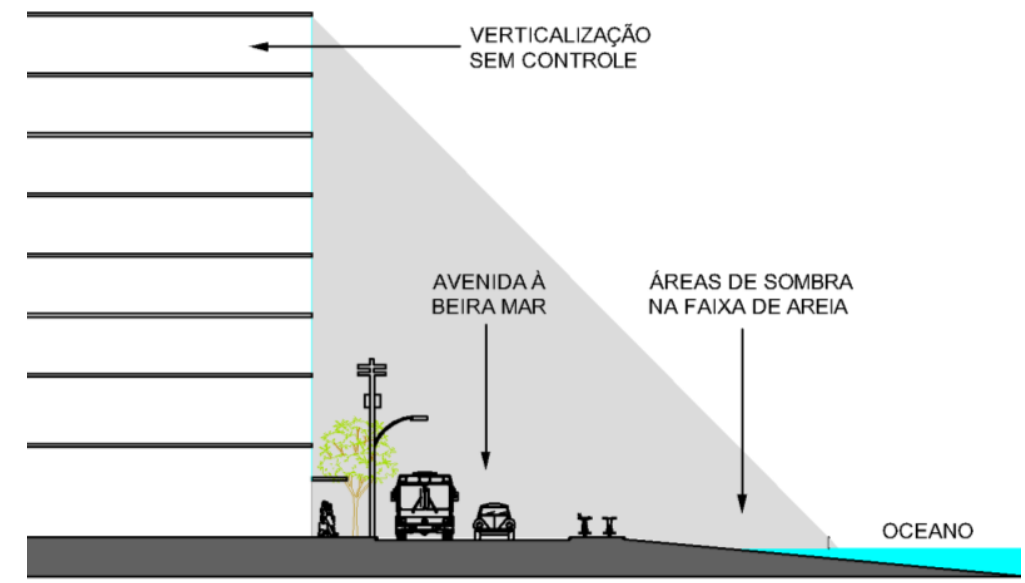

Fonte: Autores, 2019.

Figura 2 - Esquema gráfico exemplificando a importância da permeabilidade física nos empreendimentos turísticos situados à beira mar

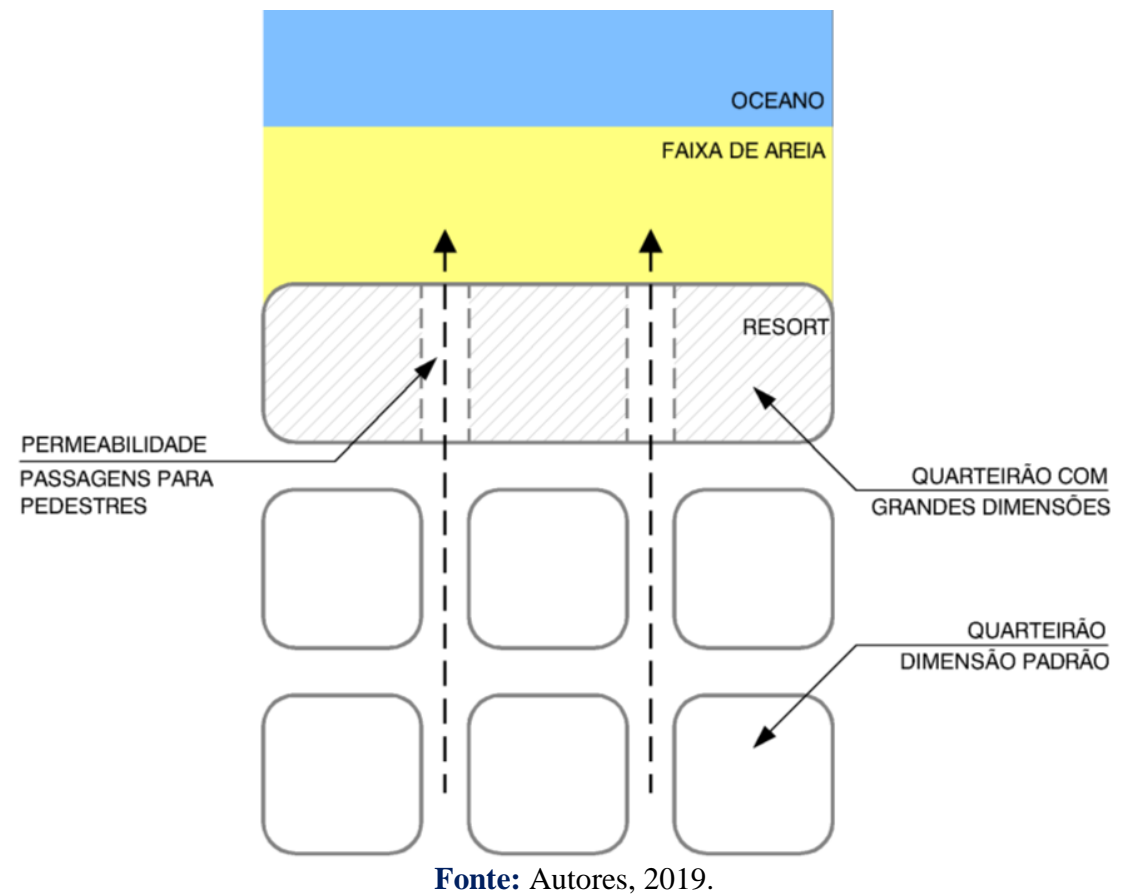


O planejamento turístico também está vinculado a uma transformação previamente orientada pelos interesses da comunidade. Para Beni (1999), planejamento é o processo de interferir e programar os fundamentos definidos do turismo que, conceitualmente, abrange em três pontos essenciais e distintos: (a) estabelecimento de objetivos, (b) definição de cursos de ação e determinação da realimentação.

A construção de hotéis e pousadas é essencial para a oferta de leitos numa cidade turística e ajuda na geração de empregos. Contudo, bairros ocupados majoritariamente por hotéis podem gerar um aumento no preço dos aluguéis e no custo de vida da região. Esse processo gera uma expulsão natural da população moradora, gentrificando ${ }^{5}$ o local que passa a ser frequentado apenas por turistas ou por pessoas com poder aquisitivo mais alto (RIBEIRO, 2014). Com o passar do tempo há diminuição da diversidade de pessoas e da variedade de estabelecimentos comerciais e de serviços - que passam a atender apenas a uma população flutuante. O lugar se torna artificial e deixa de ser atrativo (FERRAZ, 2013).

Situação parecida ocorre em cidades litorâneas que reservam porções significativas de seus territórios para a implementação de bairros de uso estritamente residencial que abrigam casas ou apartamentos de veraneio (leia-se bairros de veraneio). Se, durante o período das férias esses bairros permanecem lotados, no resto do ano eles ficam vazios se transformado em locais inseguros ${ }^{6}$ e caros para serem mantidos pela prefeitura.

A mistura de usos é vista como positiva na cidade hospitaleira pois atrai uma quantidade maior e mais variada de pessoas a qualquer hora do dia e da noite. Essa variedade de usos facilita a vida do morador (e do turista), que passa a ter uma série de atividades urbanas ao seu alcance. Para Jacobs (2000, p. 178):

Quanto mais complexa for a mistura de grupos de usuários - e daí sua eficiência -, maior será o número de serviços e lojas necessário para pinçar sua clientela dentre todos os tipos de grupos de pessoas, e consequentemente maior será o número de pessoas atraídas.

A implementação de um zoneamento misto pode ser o primeiro passo para que determinados trechos urbanos dotados de infraestrutura urbana básica (com postes de iluminação e de telefonia, placas de sinalização, sistema de abastecimento de agua e esgoto

\footnotetext{
${ }^{5}$ A palavra gentrificação é uma tradução do inglês (gentrification) e está associada a ideia de "origem nobre, pessoas bem nascidas e de classe social alta".

${ }^{6}$ Do ranking de municípios do Estado de São Paulo expostos a crimes violentos em 2018, quatro das dez cidades estão situadas no litoral. São eles: Itanhaém, Mongaguá, Caraguatatuba e Ubatuba. Fonte: Porta de notícias do G1. https://g1.globo.com/sp/santos-regiao/noticia/2019/05/09/estudo-considera-itanhaem-a-cidade-mais-violenta-de-saopaulo.ghtml Acesso maio de 2019.
} 
instalados, arborização viária e calçadas largas) otimizem o território através da diversidade de usos e atividades evitando sua ociosidade e garantindo uma ocupação mais inclusiva, humana e segura (DIAS \& JÚNIOR, 2017).

Essa variedade de usos pode ser complementada com o incentivo na construção de edifícios multifuncionais que revelam um nova relação com a rua, pois permitem a implementação de cafés, restaurantes ou lojas nos pavimento térreo valorizando o convívio e o prazer de vivenciar a cidade (FERRAZ, 2013).

Não se trata de adequar o território urbano para atender todas as necessidade do turista. O planejamento turístico é um tipo de tomada de decisão que deve englobar a elaboração de políticas e lidar com um conjunto de decisões interdependentes ou sistematicamente relacionadas, e não com decisões individuais (HALL, 2001).

\section{Hospitalidade Urbana e Legislação Urbanística: conceitos e convergências}

Motivada por diversas razões, sociais, religiosas, culturais e econômicas, a hospitalidade é uma atividade milenar. Camargo e Lashley se dispuseram a criar "modelos" para facilitar os estudos sobre hospitalidade. Camargo (2003) define hospitalidade como o ato de receber, hospedar, alimentar e entreter pessoas fora de seu hábitat e entende que a hospitalidade, enquanto instância social, se desenvolve em quatro categorias: doméstica, pública, comercial e virtual. Vale mencionar que a hospitalidade urbana é derivada da hospitalidade pública.

Já para Lashley (2004), a hospitalidade consiste no conjunto de comportamentos originários da base da sociedade e se manifesta nos domínios social, privado e comercial.

Esta pesquisa utiliza a classificação de Camargo (2004) e entende a hospitalidade como uma ciência abrangente e multidisciplinar que estuda tanto as necessidades do turista como as relações sociais que se estabelecem entre o anfitrião e o hóspede num determinado espaço. E, em função das características desse espaço, são definidos os tipos de hospitalidade e as ações e responsabilidades de seus agentes. Ou seja, trata-se do espaço doméstico - a casa; o espaço comercial - o hotel; ou o espaço da cidade - o espaço público (Ver Quadro - 1). 
Quadro 1 - Esferas da hospitalidade, seus tipos de espaço e seus agentes

\begin{tabular}{|l|l|l|l|}
\hline \multicolumn{4}{|c|}{ ESFERAS DA HOSPITALIDADE } \\
\hline & Doméstica & Comercial & Urbana \\
\hline Espaço & Casa & Hotel & $\begin{array}{l}\text { Espaço } \\
\text { público }\end{array}$ \\
\hline Agentes & $\begin{array}{l}\text { Anfitrião: } \\
\text { dona da } \\
\text { casa } \\
\text { Hóspede: } \\
\text { visitante }\end{array}$ & $\begin{array}{l}\text { Anfitrião: } \\
\text { dono do } \\
\text { hotel } \\
\text { Hóspede: } \\
\text { turista }\end{array}$ & $\begin{array}{l}\text { Anfitrião: } \\
\text { gestor } \\
\text { público } \\
\text { Hóspede: } \\
\text { morador } \\
\text { ou turista }\end{array}$ \\
\hline
\end{tabular}

Fonte: Elaborados pelos autores com base em Ferraz (2013).

A esfera hospitalidade urbana se difere em muitos aspectos das outras duas esferas da hospitalidade (a doméstica e a comercial). Um dos motivos dessa diferença está no tipo de espaço da acolhida. Enquanto nas outras esferas da hospitalidade, o espaço encarregado para sediar as relações sociais entre hóspede e anfitrião é um espaço privado (ou um espaço privado de uso público), na hospitalidade urbana é o espaço público. Isso altera a compreensão de quem são e quais são as responsabilidade dos agentes da hospitalidade urbana (SEVERINI, 2013).

A figura que representa o anfitrião urbano está normalmente associada ao gestor público ou a algum representante legal do povo, como o prefeito, o secretário de planejamento ou de obras. Afinal, do ponto de vista jurídico, o espaço público está sob a jurisdição do Estado e pode sofrer alterações físicas a qualquer instante em prol do bem comum. Já o hóspede urbano engloba todos os que consomem ou vivem a experiência da cidade, incluindo os visitantes que não pernoitam na cidade. Segundo Severini (2013, p. 06):

O morador quando visita um novo museu, um centro cultural recém-inaugurado, um centro de exposições, uma praça, uma avenida reformada, se torna um turista ou um morador que visita a própria cidade.

Não é uma questão de afirmar que morador seja turista ou turista seja morador, mas parece razoável tratar turistas e moradores como sujeitos da mesma atividade compartilhando espaços e serviços urbanos (ALLIS, 2012). Nesse sentido, a hospitalidade urbana vai além da oferta de instalações adequadas por parte do poder público, ela confia papéis aos demais atores da cidade, incluindo os próprios moradores, que partilham do papel de anfitrião, responsabilizando-se pelo cuidado com o espaço público e pela gentileza no trato com as pessoas (SEVERINI \& VARGAS, 2017).

A cidade hospitaleira, portanto, ao mesmo tempo em que exige do poder público a oferta de espaços públicos de qualidade não exime a população de suas obrigações cívicas e morais. 
E isso pode ser visto como um ciclo, como o ciclo do dar-receber-retribuir. Por esta razão, Ferraz (2013) aproxima a discussão sobre a hospitalidade urbana ao sistema de dádiva de Marcel Mauss (2003).

Porém, o sucesso na qualificação do espaço público está atrelado ainda a maneira pela qual este se relaciona com o espaço privado. A sensação de hospitalidade pode ser percebida não só pela oferta de ruas iluminadas e sinalizadas, de calçadas bem pavimentadas e largas, pela presença de mobiliário urbano (como lixeiras, bancos para sentar e floreiras), mas também pela maneira com que as construções em âmbito privado se dispõe na cidade (SEVERINI \& VARGAS, 2017).

Poucos autores se dispuseram a identificar os elementos urbanos responsáveis pela condição de cidade hospitaleira. Há inúmeros estudos que focam na hospitalidade urbana, mas tiveram como objeto casos pontuais, tais como o de Dias (2006), Sagi (2008) e Quiararia (2018). Pode-se afirmar que apenas dois autores brasileiros se aventuraram até o momento nessa investigação, são eles Lucio Grinover (2007; 2016) e Valéria Ferraz (2013).

Para Grinover (2007), uma cidade é hospitaleira em função da coexistência de três dimensões fundamentais: acessibilidade, legibilidade e identidade, intimamente relacionadas com a "escala" e com as medidas geográficas e temporais que proporcionam a compreensão da cidade, seja para o morador seja para o turista. Em seu último trabalho, Grinover (2016) expandiu a dimensão acessibilidade para mobilidade e incluiu a dimensão cidadania.

Para Ferraz (2013) há certa dificuldade em identificar esses elementos pois a hospitalidade urbana é resultado de uma somatória de sensações derivadas de atributos tangíveis (mensuráveis) e de atributos intangíveis (imensuráveis). Os atributos tangíveis são aqueles de ordem física e espacial que podem ser identificados e incorporados em leis específicas de desenvolvimento urbano. Já os atributos intangíveis são de natureza psicológica e subjetiva e dizem respeito as experiências anteriores e memórias de cada um e que, de alguma forma, dialogam, ou não, com a cidade a ser visitada. A autora concentra seus estudos apenas nos atributos tangíveis, pois só eles é que podem ser classificados, mapeados e implementados pelo gestor público.

Tomando como base o trabalho de Grinover (2007) e numa vasta investigação sobre estudos relacionados a paisagem e ao desenho urbanos, Ferraz (2013) estabeleceu, a partir de seus atributos tangíveis, quatro atributos espaciais de hospitalidade urbana que podem ser incorporados às políticas públicas de desenvolvimento urbano. São eles: diversidade, 
permeabilidade, legibilidade e conforto. Estudos recentes (SEVERINI, 2015; SEVERINI, 2016; SEVERINI \& VARGAS, 2017) demonstram que esses atributos podem ser incorporados em leis que tratam do ordenamento territorial, como o Plano Diretor e a Lei de Zoneamento.

No atual Plano Diretor Estratégico do Município de São Paulo - PDE (Lei 16.050/14), por exemplo, percebe-se a incorporação dos atributos espaciais de hospitalidade urbana no item "Parâmetros qualificadores da ocupação", inserido no Capítulo I da referida Lei. Visando a qualificação do espaço público, os atributos espaciais de hospitalidade urbana estão "embutidos" em alguns parâmetros de ocupação do solo. Podemos citar: fruição pública (incentivo urbanístico que estimula a permeabilidade física no pavimento térreo de edifícios), fachada ativa (instrumento que busca incentivar a diversidade de usos por meio da implementação de estabelecimentos comerciais no pavimento térreo e outros usos nos andares superiores, e ainda estimula que a fachada tenha vedação transparente contribuindo para a geração de permeabilidade visual), limite de vedação do lote (incentivo a permeabilidade visual), destinação de área para alargamento do passeio público (incentivo urbanístico para aumentar o conforto).

Já no Plano Diretor de Ilhabela (SP) é possível verificar a incorporação do atributo legibilidade. O Artigo 27 incentiva a "preservação da paisagem e sua ambiência, permitindo sua observação pública ao longo da rodovia SP-131” dentro do Corredor de Desenvolvimento Turístico - que compreende todas as áreas da Orla Marítima ao longo da rodovia com malha viária estruturada. Essa diretriz se consolida numa regra de uso e ocupação do solo que prevê "respeitar a altura máxima da edificação em 8 metros, medidos a partir de uma reta paralela obtida a partir do traçado natural do terreno". E no Plano Diretor do Guarujá, SP, o Artigo 14 incorpora o atributo conforto ao "garantir a insolação das praias, impedindo intervenções urbanas e edilícias que provoquem o sombreamento das áreas públicas de banho, excetuandose as áreas de alta densidade, já edificadas em seus conjunto".

\section{METODOLOGIA}

Para dar conta de atender os objetivos propostos foram utilizadas naturezas metodológicas semelhantes. Utilizou-se pesquisa documental e pesquisa bibliográfica.

A busca pelos dados documentais se deu praticamente on-line. A coleta de leis, decretos e planos foi obtida através da internet, mais especificamente pelos sites do Ministério do Turismo e dos Órgãos Estaduais de Turismo estudados. Tal busca teve como intuito introduzir 
o tema discutido e debater acerca de sua importância no contexto turístico atual. Em paralelo, foram feitas avaliações sobre o Programa de Regionalização do Turismo e Mapa do Turismo Brasileiro.

As leis estaduais de turismo foram analisadas com o intuito de investigar se há algum tipo de incentivo para que as cidades, que se diziam turísticas, elaborassem seus Planos Diretores.

A pesquisa se caracteriza por ser qualitativa, de caráter exploratório e com o uso do método de análise documental, tal como apresentado por Corsetti (2006) e Sá-Silva et al. (2009).

\section{ANÁLISE E DISCUSSÃO DOS RESULTADOS}

\section{O Mapa do Turismo Brasileiro e as cidades turísticas dos estados do sul}

A base utilizada pelos três Estados do sul do país para classificar suas cidades turísticas é o Programa de Regionalização do Turismo do governo federal. Regulamentado pela Portaria $n^{\circ} 105$ de 2013, o programa busca:

Subsidiar a estruturação e qualificação dessas regiões, buscando fortalecer a identidade local e possibilitando a consolidação de novos roteiros como produtos turísticos rentáveis e competitivos, nos mercados nacional e internacional.

A ideia da regionalização é estimular a participação de todos os municípios participantes de uma mesma região com vocação turística, inclusive os que não tem infraestrutura para tal. Assim, os municípios menos propensos ao turismo podem se beneficiar dos benefícios dados pelo Programa, o que inclui verbas financeiras e serviços para qualificação de mão-de-obra.

Como parte do Programa, foi elaborado o Mapa do Turismo Brasileiro - instrumento que orienta a atuação dos Órgãos Estaduais de Turismo no desenvolvimento das políticas públicas. De acordo com informações do Ministério do Turismo, há necessidade de identificação e classificação das cidades para que as políticas públicas e investimentos sejam mais adequados à realidade de cada região. Isso vem ao encontro do que se defende nesse artigo, contudo os critérios que norteiam a escolha das cidades turísticas e a forma com que elas foram classificadas reforça a falta de compatibilização entre desenvolvimento turístico e planejamento urbano. 
A Portaria n. 144 de 27 de Agosto de 2015 estabelece a categorização dos municípios das regiões turísticas do Mapa do Turismo Brasileiro. Os municípios foram agrupados em cinco diferentes categorias, definidas como A, B, C, D e E. De acordo com o Anexo I da referida Portaria, as variáveis utilizadas na categorização dos municípios são praticamente apenas de caráter econômico. Leva-se em consideração:

a) o número de estabelecimentos formais cuja atividade principal é hospedagem;

b) o número de empregos formais no setor de hospedagem;

c) a estimativa de turistas a partir do Estudo de Demanda Doméstica;

d) a estimativa de turistas a partir do Estudo de Demanda Internacional.

O mapa abaixo (Figura 3) mostra o Mapa do Turismo Brasileiro para a Região Sul. Santa Catarina é o estado que tem cidades classificadas na categoria "A", totalizando 3 municípios: Florianópolis, Balneário de Camboriú e Bombinhas. Os estados do Paraná e Rio Grande do Sul tem 2 municípios na categoria “A”. São eles: Curitiba e Foz do Iguaçu, Porto Alegre e Caxias do Sul, respectivamente. Como os municípios da categoria "A" são, de forma geral os mais populosos, em tese, eles já são obrigados a elaborar seus Planos Diretores. O incentivo à elaboração dos Planos Diretores deveria ocorrer para os municípios das outras categorias.

Figura 3 - Ilustração que mostra o Mapa do Turismo Brasileiro na Região Sul

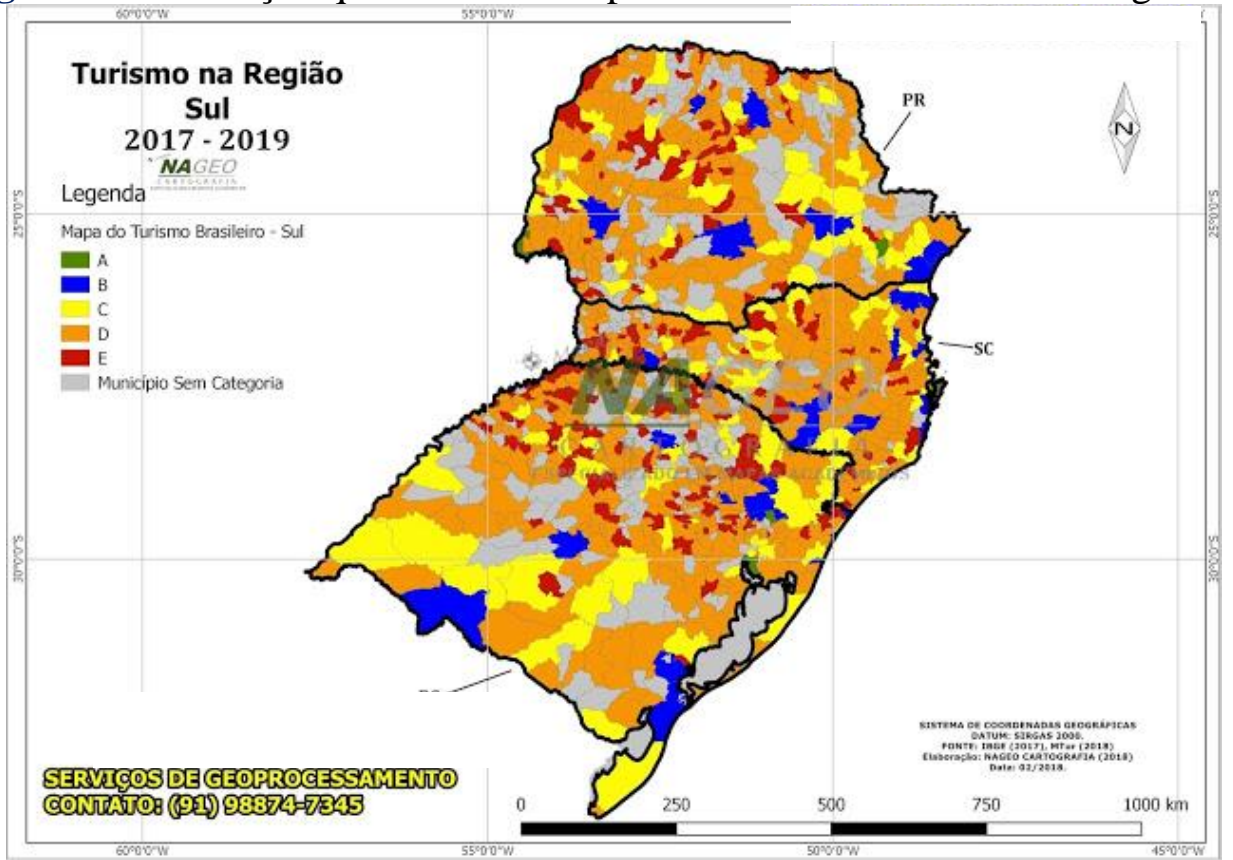

Fonte: https://mapasnageocartografia.blogspot.com/2018/02/mapa-do-turismo-brasileiro_40.html 
São exigidas poucas informações para a cidade integrar a Região Turística do Mapa do Turismo Brasileiro. De acordo com a Portaria n. 205 de 9 de Dezembro de 2015, cada município deverá atender aos seguintes critérios:

a) possuir órgão responsável pela pasta de turismo (Secretaria, Fundação, Coordenadoria, Departamento, Diretoria, Setor ou Gerência);

b) comprovar a existência de dotação para o turismo na lei orçamentária anual vigente;

c) apresentar Termo de Compromisso assinado por Prefeito Municipal ou dirigente responsável pela pasta de turismo, conforme modelo disponibilizado, aderindo de forma espontânea e formal ao Programa de Regionalização do Turismo e à Região Turística.

Não foram consideradas as categorias sugeridas pela Lei $n^{\circ}$. 6.513/1977, que define critérios para as Áreas Especiais e de Locais de Interesse Turístico. Também não se leva em consideração se a cidade possui um inventário turístico (exigido no Plano Nacional de Turismo e na Lei que estabelece as normas sobre a Política Nacional de Turismo - Lei 11.771/2008), tampouco Planos Diretores ou Planos Diretores de Turismo.

A atualização do Mapa do Turismo Brasileiro deve ser ocorrer periodicamente. A última atualização, Portaria n. 192 de 27 de dezembro de 2018, sugere, mas de ordem facultativa, outras exigências para a cidade fazer parte do programa. Leva-se em consideração a partir de agora a "existência de diretrizes de turismo no Plano Diretor" e a "existência de Plano Municipal de Turismo", além de um "Fundo Municipal para o Turismo".

De acordo com as informações obtidas junto ao site do Ministério do Turismo, os órgãos estaduais de turismo devem promover discussões (reuniões e oficinas participativas) com as regiões e municípios e definir o mapa de cada estado.

O Mapa estadual deve ser validado no Fórum ou Conselho Estadual de Turismo e aprovado pelo Secretário do Órgão Oficial de Turismo daquela Unidade da Federação, antes de ser encaminhado ao Ministério do Turismo. Uma vez inseridos no Mapa do Turismo Brasileiro, os municípios podem solicitar recursos financeiros, técnicos e humanos do governo federal.

O Mapa do Turismo Brasileiro de 2017 conta com 3.285 municípios situados em 328 regiões turísticas no mapa de 2017. Ora, um país que há anos não consegue sair da marca de 6 
(seis) milhões de turistas internacionais por ano $^{7}$ e que perde posições ano a ano no ranking dos países mais visitados do mundo, deveria rever os critérios que classificam suas cidades como turísticas. Os cinco Estados estudados nessa pesquisa possuem, juntos, 1.330 municípios considerados turísticos ${ }^{8}$. Apenas como comparação, a França, o pais mais visitado do planeta ${ }^{9}$, possui uma quantidade infinitamente menor de municípios turísticos e seu povo não é conhecido como um povo hospitaleiro.

O Rio Grande do Sul é o único dos cinco estados estudados que não possui uma legislação estadual própria de turismo. Representado pela Secretaria de Turismo (SETUR), o Estado gaúcho conta apenas com o "Plano de Desenvolvimento do Turismo do Rio Grande do Sul 2012-2015". Dentre os cinco desafios estabelecidos no Plano para o desenvolvimento do turismo no Estado, destaca-se o de "implantar um sistema de gestão do turismo" que prevê, entre outros indicadores, a elaboração de um Plano Diretor de Turismo junto com um sistema de monitoramento e avaliação de ações.

Santa Catarina, representado pela Secretaria de Estado de Turismo, Cultura e Esporte trabalha em conjunto com a SANTUR (Santa Catarina Turismo S/A). A Lei 13.792/2006, dispõe sobre o Plano Estadual da Cultura, do Turismo e do Desporto do Estado de Santa Catarina (PDIL), que define diretrizes e critérios relativos aos programas e subprogramas que prevê. A parte da Lei que trata do Programa de Desenvolvimento do Turismo (Item IV) dentro do Artigo $5^{\circ}$, é possível verificar uma preocupação com a qualidade do espaço público e serviços públicos. Os itens abaixo demostram uma vontade de compatibilizar as necessidades do turista sem prejudicar a população.

7. apoio à implantação de saneamento básico em destinações turísticas;

8. estímulo ao tratamento adequado de resíduos sólidos em destinações turísticas;

9. busca de parcerias com órgãos públicos competentes para a viabilidade da estruturação de atrativos e espaços turísticos;

10. incentivo à ampliação da malha aérea nacional e internacional;

\footnotetext{
${ }^{7}$ De acordo com as informações disponíveis nos “Anuários Estatísticos de Turismo”, de 2009 a 2014, a chegada de turistas ao Brasil só passou da marca de 6 (seis) milhões em 2014.

${ }^{8}$ De acordo com o Mapa de Turismo Brasileiro de 2017, os cinco estados estudos tem as respectivas regiões turísticas e municípios turísticos: a) Mato Grosso do Sul - 10 regiões turísticas e 60 municípios turísticos; b) Santa Catarina - 12 regiões turísticas e 184 municípios turísticos; c) Rio Grande do Sul - 27 regiões turísticas e 371 municípios turísticos; d) Paraná 14 regiões turísticas e 283 municípios turísticos; e) São Paulo - 51 regiões turísticas e 432 municípios turísticos.

${ }^{9}$ De acordo com a OMT (Organização Mundial do Turismo), a França é o país mais visitado no mundo. Em 2016 recebeu cerca de 85 (oitenta e cinco) milhões de turistas.
} 
Santa Catarina conta ainda com um Plano de Marketing Turístico de Santa Catarina 2020 denominado: "Plano Catarina: turismo, qualidade, diversidade".

Na mesma linha de Santa Catarina, o Paraná tem um política de turismo que parece se preocupar com a infraestrutura da cidade. Ainda assim, não sugere a elaboração de Planos Diretores em suas cidades turísticas. O Estado do Paraná conta com a Lei no 15.973/2008, denominada Política de Turismo do Paraná. No Artigo $2^{\circ}$ da Lei, estão definidos conceitos importantes sobre o tema. Além da definição de turismo, região turística, oferta turística etc., a Lei define municípios turísticos e municípios com potencial turístico como:

III - Municípios Turísticos são aqueles consolidados, determinantes de um turismo efetivo, capazes de gerar deslocamentos e estadas de fluxo permanentes.

IV - Municípios com potencial turístico são aqueles possuidores de recursos naturais e culturais expressivos, encontrando no turismo diretrizes para seu desenvolvimento socioeconômico, ainda não apresentando fluxo turístico efetivo.

Os conceitos ajudam, porém não é solicitada a elaboração de lei estadual e nem uma comissão para analisar cada caso, o que deixa a escolha das cidades turísticas um tanto quanto subjetiva. Por outro lado, o Estado disponibiliza uma apostila para "Orientação para Gestão Municipal de Turismo" e nela reforça a importância do elaboração do Plano Diretor, do Plano Diretor de Turismo e da importância da participação popular e da sociedade civil nesse processo.

Constata-se na apostila o reconhecimento que turistas e moradores de certa localidade fazem uso de um mesmo território, existindo a necessidade da integração do Turismo no Plano Diretor dos municípios. De acordo com a apostila, o planejamento urbano:

(...) dá ênfase a outras funções dos municípios, como as comerciais, administrativas, industriais, residenciais, entre outras, nota-se que a maioria dos esforços do poder público são voltados para atender essencialmente as necessidades da população local e não especificamente ao turismo (pag. 32).

\section{Criatividade e organização no planejamento turístico dos Estados de Mato Grosso do Sul e São Paulo}

O Estado de Mato Grosso do Sul, apesar de contar com uma política estadual de turismo deixa, assim como os três estados do Sul, a cargo do governo federal a escolha de suas cidades turísticas. No Artigo $3^{\circ}$ da Lei que estabelece a Política Estadual de Turismo e Plano Estadual 
de Turismo (Lei 5.224/2018) informa sobre os "Municípios constantes no Mapa Turístico do Estado".

Mas o estado mais hospitaleiro do pais também estimula o planejamento turístico nas cidades de outra forma, alternativa e inovadora. Destaca-se aqui o "Programa de Classificação dos Municípios" que foi baseada no "Ciclo de vida das destinações turísticas". Criado pela Fundação de Turismo do Estado do Mato Grosso do Sul, o Programa tem como objetivo geral "fortalecer o turismo em Mato Grosso do Sul no que diz respeito ao desenvolvimento da infraestrutura e consequentemente atração de novos investimentos". Foram elaborados quatro critérios (a seguir elencados) para classificar as cidades turísticas. Cada critério tem um peso que interfere na classificação. São eles:

- Governança: Peso: 25,11\%;

- Gestão pública municipal: Peso: 9,96\%;

- Sustentabilidade do município: Peso: $13,85 \%$;

- Infraestrutura turística: Peso: 51,08\%.

Após a pontuação, o potencial turístico de cada município foi classificado em: semear, nascer, frutificar e colher. Se a cidade está na categoria semear, por exemplo, tem menos demanda turística e menos infraestrutura. Já na outra ponta está o colher, classificação para cidades que já tem o turismo como uma das principais atividades econômicas. Os municípios com maior pontuação e pertencentes as categorias frutificar e colher, recebem recursos financeiros da Fundação de Turismo de Mato Grosso do Sul (FUNDTUR). Já os de menor pontuação recebem apoio técnico e cursos de capacitação.

As análises foram feitas nos anos de 2013, 2014 e 2017. Dos 79 municípios do Estado, 42 participaram do Programa. 
Figura 4 - Mapa com o classificação dos municípios do Estado de Mato Grosso do Sul

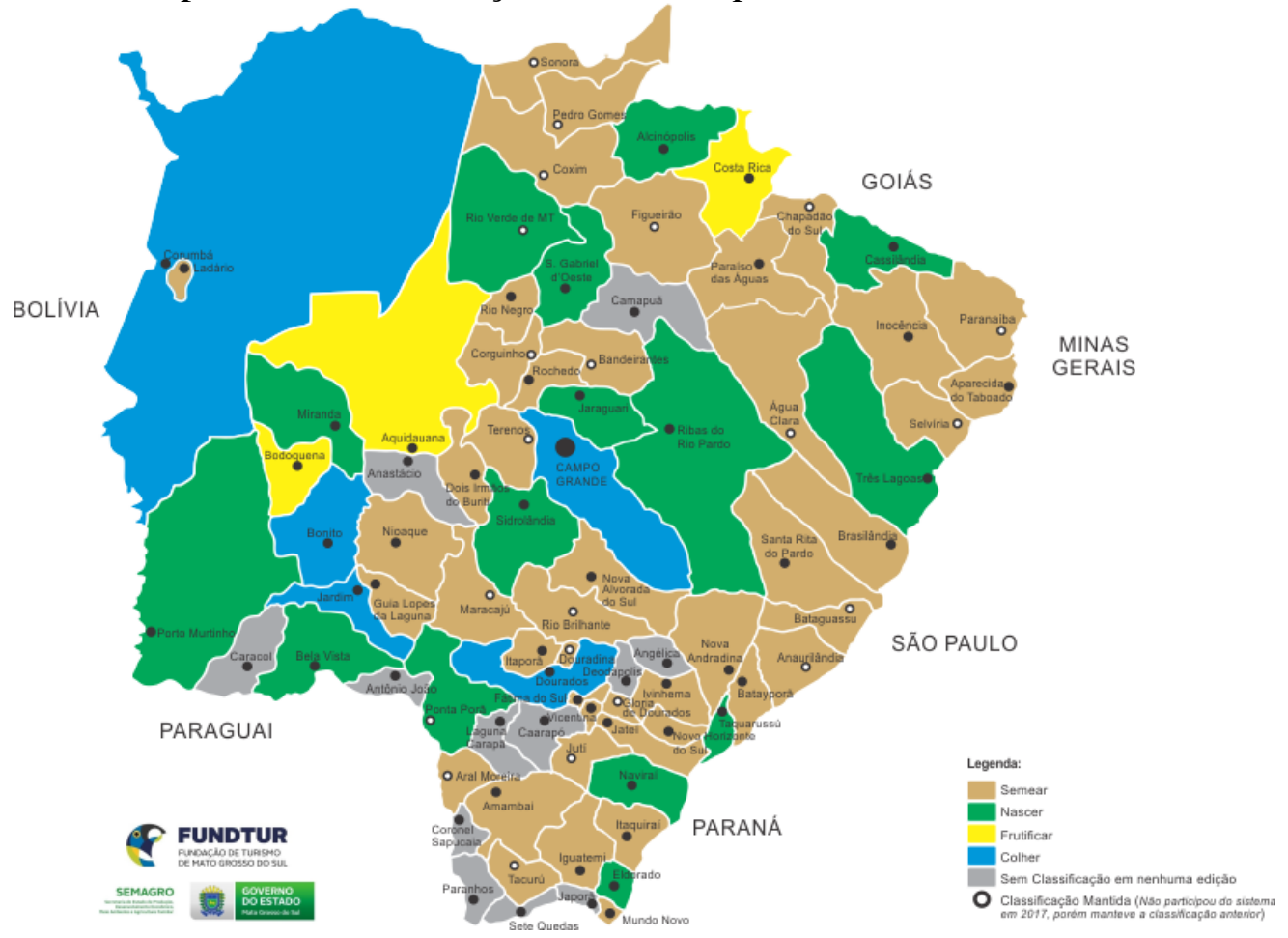

Fonte: http://www.turismo.ms.gov.br/classificacao-de-municipios-2013-2014-2017/

São Paulo é o único dos cinco estudados que possui lei específica para a classificação de cidades turísticas e que não segue, necessariamente, os critérios do Mapa do Turismo Brasileiro. Representado pela Secretaria de Turismo do Estado de São Paulo, o turismo paulista exige a elaboração de lei estadual para cada cidade (turística) após observadas as condições e atendidos os requisitos mínimos estabelecidos em Lei Complementar (Lei 1.261/15). Apenas com um projeto de lei aprovado as cidades turísticas paulistas podem solicitar recursos do Fundo de Melhorias dos Municípios Turísticos - FUMTUR.

As cidades turísticas (ou Municípios Turísticos) são classificadas em duas categorias: Estâncias Turísticas e Municípios de Interesse Turístico (MIT). Ver Figura abaixo as Estâncias na cor rosa e os MITs na cor azul. 
Figura 5 - Mapa do Estado de São Paulo com a localização das Estâncias Turísticas e dos MITs

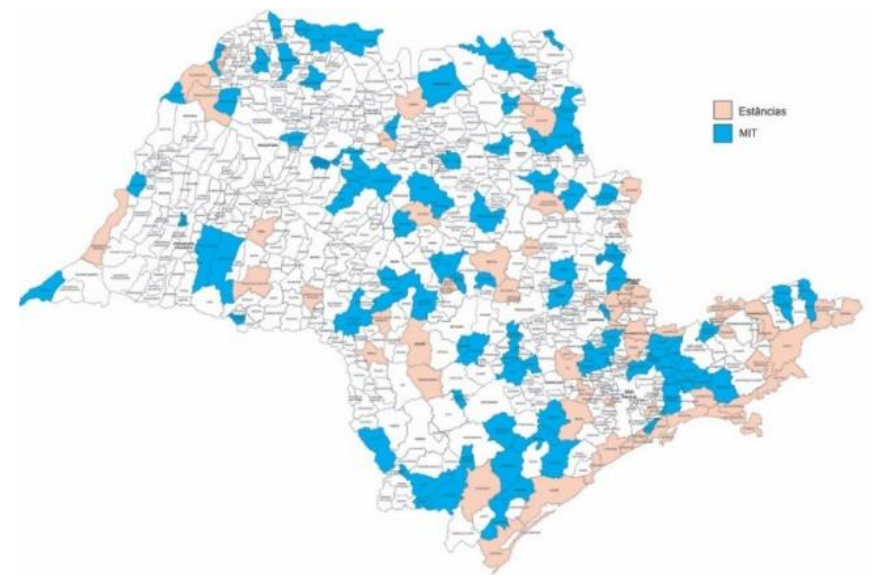

Fonte: http://www.turismo.sp.gov.br/publico/noticia_tour.php?cod_menu=111

As Estâncias Turísticas foram as primeiras definidas por Lei, sendo as cidades litorâneas as primeiras a obterem o título (ver Tabela 1). Existem quatro tipos de Estâncias Turísticas: balneárias, hidrominerais, climáticas e turísticas (RAIMUNDO et. al., 2010).

Tabela 1 - Relação de cidades classificadas como Estâncias Turísticas do tipo Balneárias

\begin{tabular}{|r|l|l|l|l|}
\hline \multicolumn{5}{|c|}{ ESTÂNCIAS BALNEÁRIAS } \\
\hline Item & Cidade & Projeto Lei - Estância & Região Adminstrativa & População \\
\hline 1 & Bertioga & Lei 8.512/1993 & Santos & 61.736 (IBGE 2018) \\
\hline 2 & Cananéia & Lei 163/1948 & Registro & 12.539 (IBGE 2018) \\
\hline 3 & Caraguatatuba & Lei 38/1947 & São José dos Campos & 116.786 (IBGE 2017) \\
\hline 4 & Guarujá & Lei 163/1948 & Santos & 380.527 (IBGE 2018) \\
\hline 5 & lguape & Lei 163/1948 & Registro & 30.256 (IBGE 2014) \\
\hline 6 & llha Comprida & Lei 9.072/1995 & Registro & 10.965 (IBGE 2018) \\
\hline 7 & Ilhabela & Lei 163/1948 & São José dos Campos & 32.197 (IBGE 2015) \\
\hline 8 & Itanhaém & Lei 163/1948 & Santos & 100.496 (IBGE 2018) \\
\hline 9 & longaguá & Lei 1.482/1977 & Santos & 55.731 (IBGE 2018) \\
\hline 10 & Peruibe & Lei 344/1974 & Santos & 67.548 (IBGE 2018) \\
\hline 11 & Praia Grande & Lei 2.140/1979 & Santos & 319.146 (IBGE 2018) \\
\hline 12 & Santos & Lei 2.139/1979 & Santos & 434.742 (IBGE 2017) \\
\hline 13 & São Sebastiao & Lei 163/1948 & São José dos Campos & 73.942 (IBGE 2010) \\
\hline 14 & São Vicente & Lei 1.358/1977 & Santos & 360.380 (IBGE 2017) \\
\hline 15 & Ubatuba & Lei 163/1948 & São José dos Campos & 89.747 (IBGE 2018) \\
\hline
\end{tabular}

Fonte: Autores, 2019.

$\mathrm{O}$ artigo $2^{\circ}$ da Lei Complementar 1.261/15 define as condições indispensáveis e cumulativas para a classificação de Estância Turística e o artigo $4^{\circ}$ define as condições para a classificação de Município como de Interesse Turístico (MIT). O projeto de lei para classificação do município como Estância Turística ou como Município de Interesse Turístico (MIT) poderá ser apresentado por qualquer Deputado, devidamente instruído com uma série de 
documentos. Cabe a Comissão da Assembleia Legislativa apreciar os projetos de lei de classificação de municípios turísticos, encaminhar os documentos quem trata este artigo à Secretaria de Estado competente para os assuntos relacionados ao turismo, para sua manifestação quanto ao cumprimento dos requisitos estabelecidos nesta lei complementar.

Vale destacar que um dos documentos exigidos é o Plano Diretor de Turismo do Município. A Resolução da ST-14, de 21/06/2016, estabelece parâmetros para elaboração desse Plano que, basicamente deverá ser composto basicamente de:
a) Apresentação / Metodologia;
b) Inventário/Diagnóstico;
c) Prognóstico;
d) Plano de Ações.

Apesar da criatividade e organização de Mato Grosso do Sul e São Paulo, em nenhum momento os aspectos urbanísticos foram levados em consideração no planejamento turístico dos dois Estados. Existem pequenas insinuações nas leis e planos para compatibilizar turismo e planejamento urbano, como "propostas de ações conjuntas para o município" e "dispor de infraestrutura básica capaz de atender às populações fixas e flutuantes”. Mas, de fato, a grande preocupação parece ser com o aumento no fluxo de turistas e com a ideia de consolidar a qualquer preço o turismo como eixo estratégico de desenvolvimento econômico.

\section{CONCLUSÕES}

O turismo tem muito a contribuir para o desenvolvimento e crescimento de uma cidade, mas é importante que ele se desenvolva sem prejuízos aos moradores. Por esta razão, este trabalho alertou para a necessidade de elaboração do Plano Diretor em cidades turísticas.

A partir do Estatuto da Cidade, os planos diretores e as leis de parcelamento, uso e ocupação do solo ganharam novos instrumentos capazes de interferir na dinâmica da urbanização brasileira fazendo com que o usufruto da terra urbana beneficie a coletividade e não mais apenas o proprietário. Com isso, novos parâmetros de desenho urbano começaram a se difundir pelo país fornecendo novas ferramentas para os anfitriões qualificarem o espaço público, evitar a especulação imobiliária e garantir a qualidade de vida dos moradores. 
Esta pesquisa procurou ainda reforçar o conceito de hospitalidade urbana associando-a à capacidade das cidades turísticas em bem receber, oferecendo um espaço público de qualidade. Essa qualidade é marcada pela presença dos parâmetros de desenho urbano (acima citados) que, se presentes nos Planos Diretores e devidamente respeitados pela população, podem contribuir para a condição de cidade hospitaleira.

Nesse sentido, o enfoque dado para a promoção e o desenvolvimento da atividade turística deve prescindir uma série de questões que extrapolam as de ordem estatística e econômica. Por se tratar de um fenômeno social, as pesquisas e estudos que envolvem a atividade turística precisam abordar não somente os métodos tradicionais, como estudo de demanda turística e inventário do potencial turístico existente, como também analisar essa atividade do ponto de vista urbanístico. Não basta exigir a elaboração de um Plano Diretor de Turismo, como faz o Estado de São Paulo e que prevê o Rio Grande do Sul. É preciso que haja uma compatibilização das políticas públicas de turismo com o Plano Diretor Municipal.

Quando cidades passam a ser incorporadas espontaneamente no circuito das localidades turísticas, o planejamento urbano torna-se a principal ferramenta para fazer com o turismo não comprometa a qualidade de vida dos moradores. Caso contrário, há uma chance da cidade passar a ter territórios "consumidos" pela prática do turismo induzindo uma reconfiguração espacial que não necessariamente dialoga com a paisagem urbana e nem com a infraestrutura local. Situação que parece estar ocorrendo nos Estados do sul do país que contam apenas com os critérios classificatórios do Mapa do Turismo Brasileiro, apontados aqui como insuficientes. Por outro lado, os Estados de Mato Grosso do Sul e São Paulo, ao desenvolverem maneiras alternativas e independentes de classificação para seus municípios turísticos, parecem estar à frente nesse processo.

Tornar uma cidade hospitaleira é um desafio para os gestores públicos e para a população, por isso está na hora de repensar a hospitalidade (urbana) no Brasil.

\section{Referências}

ALLIS, Tiago. (2012). Projetos urbanos e turismo em grandes cidades: o caso de São Paulo. Tese de doutorado. FAU USP. São Paulo.

BARDIN, Laurence. (2011). Análise de conteúdo. São Paulo: Edições 70.

BARRIOS, Sônia. (1986). A produção do espaço. In SOUZA, Adélia de e SANTOS, Milton (Org.). A construção do espaço. São Paulo: Nobel. 
BENI, M. (1999). Política e estratégia do desenvolvimento regional: planejamento integrado e sustentável do turismo. Turismo em Análise, 10(1), 7-17.

BRASIL.(2018). Portaria n ${ }^{\circ}$. 192, de 27 de Dezembro de 2018. Estabelece critérios para a atualização do Mapa do Turismo Brasileiro. Brasília: Poder Executivo.

BRASIL.(2015). Portaria nº. 144, de 27 de Agosto de 2015. Estabelece a categorização dos municípios pertencentes às regiões turísticas do Mapa do Turismo Brasileiro. Brasília: Poder Executivo.

BRASIL. (2013). Portaria no . 105, de 16 de Maio de 2013. Institui o Programa de Regionalização do Turismo e dá outras providências. Brasília: Poder Executivo.

BRASIL.(2008). Política Nacional de Turismo: Lei no . 11.771, de 17 de Setembro de 2008. Define as atribuições do Governo Federal no planejamento, desenvolvimento e estímulo ao setor turístico e disciplina a prestação de serviços turísticos, o cadastro, a classificação e a fiscalização dos prestadores de serviços turísticos. Brasília: Poder Executivo.

BRASIL. (2001). Estatuto da Cidade. Lei nº . 10.257, de 10 de Outubro de 2001. Estabelece diretrizes gerais da política urbana. Brasília: Câmara dos Deputados, Coordenação de Publicações.

BRASIL. (1977). Lei no . 6.513, de 20 de Dezembro de 1977. Dispõe sobre a criação de áreas especiais e de locais de interesse turístico sobre o inventário com finalidades turística dos bens de valor cultural e natural. Brasília: Poder Executivo.

BRASIL. (1981). Decreto $\mathrm{n}^{\circ}$ 86.176, de 06 de julho de 1981. Regulamenta a Lei no 6.513, de 20 de dezembro de 1977. Brasília: Poder Executivo.

CAMARGO, Luiz O. (2003). Os domínios da hospitalidade. In DENCKER, A.; BUENO, M. (orgs). Hospitalidade: Cenários e Oportunidades. São Paulo: Pioneira Thompson Learning.

CORSETTI, B. (2006). A análise documental no contexto da metodologia qualitativa: uma abordagem a partir da experiência de pesquisa do Programa de Pós-Graduação em Educação da Unisinos. UNI revista, v.1, n.1, p.32-46.

CRUZ, Rita de Cássia A. (1999). Política de turismo e (re)ordenamento de territórios no litoral do Nordeste do Brasil. Tese de doutorado. FFLCH-USP. São Paulo.

DIAS, Marina S.; JÚNIOR, Milton E. (2017) O espaço público e o lúdico como estratégias de planejamento urbano humano em: Copenhague, Barcelona, Medellín e Curitiba. Caderno Metrópole. São Paulo. V. 19. N. 39. PP. 635-663.

DIAS, Celia Maria Morais. (2006). Marcos da hospitalidade na Cidade de São Paulo: amenidades e facilidades. Revista Turismo em Análise. v. 17 n. 2, p.170-189.

FERRAZ, Valéria de Souza. (2013). Hospitalidade urbana em grandes cidades. São Paulo em foco. Tese de Doutorado. FAU USP. São Paulo. 
GRINOVER, Lucio. (2007). A hospitalidade, a cidade e o turismo. São Paulo: Aleph.

GRINOVER. Lucio. (2016). A cidade a procura da hospitalidade. São Paulo: Aleph (edição digital), 2016. Acesso em 2019.

GUARUJÁ. (2013). Lei Complementar no 156/2013. Institui o Plano Diretor do Município de Guarujá e dá outras providências. Poder Executivo.

HALL, C. (2001). Planejamento Turístico: políticas, processos e relacionamentos. São Paulo: Contexto.

ILHABELA. (2006). Lei $n^{\circ}$ 421/2006. Dispõe sobre o Plano Diretor de Desenvolvimento Socioambiental. Do Município de Ilhabela e dá outras providências. Poder Executivo.

JACOBS, J. (2000). Morte e vida de grandes cidades. São Paulo: Martins Fontes.

LASHLEY, Conrad; MORRISON, Alison (orgs.). (2004). Em busca da hospitalidade: perspectivas para um mundo globalizado. Barueri, SP: Manole.

LAPA, Tomas de Albuquerque. (2011). Grandes Cidades Constroem-se com Edifícios Grandes? Recife: Editora Universitária, UFPE.

LOBO, Yure. (2005). Planos Diretores para Municípios Inseridos em "Área de Especial Interesse Turístico". Revista Turismo. Ago. Acessado em março 2019 em https://www.revistaturismo.com.br/artigos/planodiretor.html

LOHMANN, Guilherme; PANOSSO NETTO, Alexandre. (2012). Teoria do Turismo: Conceitos, Modelos e Sistemas. 2.ed. São Paulo: Aleph.

MATO GROSSO DO SUL. (2018). Lei $n^{o}$. 5.224, de 9 de Julho de 2018. Dispõe sobre o Sistema Estadual de Turismo do Estado do Mato Grosso do Sul, a Política Pública Estadual para o Turismo e o Plano Estadual de Turismo, e dá outras providências. Mato Grosso do Sul. Poder Executivo.

MAUSS, Marcel. (2003). Sociologia e Antropologia. Volume II. São Paulo.

MENDES, Daniella Aparecida Tolão; WADA, Elizabeth Kyoko. (2016). Copa 2014: as relações de hospitalidade e hostilidade ao visitante - Brasil. PODIUM Sport, Leisure and Tourism Review. Vol.5, N. 1 Janeiro/Abril.

OLIVEIRA, Elizângela. (2014). Turismo, produção do espaço e planejamento urbano nas cidades contemporâneas. Revista Turismo: Estudos \& Práticas. RTEP/UERN.

Mossoró, RN, Vol. 3, n. 02, julho/dez.

PARANÁ. (2008). Política de Turismo do Paraná. Lei no. 15.973, de 13 de Novembro de 2008. Estabelece a Política de Turismo do Paraná, conforme especifica, e adota outras providências. Assembleia Legislativa do Estado do Paraná. 
QUIARARIA, Clarissa Campos. (2018). Hospitalidade pública: o caso da Praça Gustavo Teixeira em São Pedro, SP. Dissertação de Mestrado. Programa de Pós-Graduação em Turismo da EACH-USP.

RAIMUNDO, S. et. al. (2010). Análise da cronologia de criação das Estâncias Turísticas no Estado de São Paulo. VII Seminário da Associação Nacional Pesquisa e Pós-Graduação em Turismo (ANPTUR). Universidade Anhembi Morumbi. São Paulo.

RIBEIRO, Daniel de Albuquerque. (2014). Reflexões sobre o conceito e a ocorrência do processo de gentrification no Parque Histórico do Pelourinho, Salvador-BA. Cad. Metrópole, São Paulo, Vol. 16, n. 32, pp. 461-486. Nov.

ROLNIK, Raquel. (2009). São Paulo. São Paulo: Publifolha.

RUSCHMANN, D. (2001). Planejamento Turístico. In Ansarah, M. (Org.). Turismo. Como aprender, como ensinar. (Vol. 2). São Paulo: Senac.

SAGI, Luciana. (2008). Gestão pública da hospitalidade urbana: estudo de caso do Parque da Água Branca na cidade de São Paulo. Revista Brasileira de Pesquisa em Turismo. v. 2, n. 3, p. 90-105, nov. 2008.

SANTA CATARINA. (2006). Plano Estadual da Cultura, do Turismo e do Desporto do Estado de Santa Catarina. Lei no ${ }^{\circ}$ 13.792, de 18 de Julho de 2006. Define diretrizes e critérios relativos aos programas e subprogramas que prevê e estabelece outras providências. Santa Catarina. Poder Executivo.

SÃO PAULO. (2016). Resolução ST-14, de 21 de Junho de 2016. Estabelece parâmetros para elaboração do Plano Diretor de Turismo dos municípios e dá outras providências. São Paulo. Poder Executivo.

SÃO PAULO. (2015). Lei Complementar $n^{\circ} 1.261$, de abril de 2015. Estabelece condições e requisitos para a classificação de Estâncias e de Municípios de Interesse Turístico e dá providências correlatas. São Paulo. Poder Executivo.

SÁ-SILVA, Jackson Ronie, et.al. (2009). Pesquisa documental: pistas teóricas e metodológicas. Revista Brasileira de História \& Ciências Sociais. Ano I - Número I Julho.

SEVERINI, Valeria Ferraz; VARGAS, Heliana Comin. (2017). Rediscutindo hospitalidade urbana na Lei de Zoneamento de São Paulo de 2016. Revista Hospitalidade. Volume 14. N. 02. Ago.

SEVERINI, Valeria Ferraz. (2016). Atributos espaciais de hospitalidade urbana. p. 257-285. In VARGAS, Heliana C. \& PAIVA, Ricardo (Orgs.). Turismo, arquitetura e cidade. Barueri, SP: Manole. 
SEVERINI, Valeria Ferraz. (2015). O novo Plano Diretor Estratégico do Município de São Paulo à luz da Hospitalidade Urbana. In Anais do VII Seminário PROJETAR. Natal, UFRN.

SEVERINI, Valeria Ferraz. (2013). Hospitalidade urbana: ampliando o conceito. Revista Iberoamericana de Turismo - RITUR, Penedo, v. 3, n.2, p. 84-99.

SILVA, Alexsandro F. Cardoso; FERREIRA, Angela L. de Araújo (2007). Dinâmica imobiliária e turismo: novas relações, novos riscos. Caderno Metrópole. São Paulo. Páginas 109-133. 2. Semestre.

YÁZIGI, Eduardo. (2001). A alma do lugar. Turismo, planejamento e cotidiano. São Paulo: Contexto. 